\title{
Frequency Doubling Technology vs Standard Automated Perimetry in Ocular Hypertensive Patients
}

\author{
Italo Giuffrè* \\ Medical School, University of Roma "Tor Vergata”, Roma, Italy
}

\begin{abstract}
Background: Frequency doubling technology (FDT) perimetry measures contrast sensitivity. The magnocellular component of ganglion cells in human retina is isolated as a whole by the FDT stimulus. The aim of this study is to investigate the role of Humphrey Matrix threshold testing in the detection of early functional retinal impairment in ocular hypertensive patients compared to standard automated perimetry (SAP).

Methodology: Forty hypertensive patients were enrolled in this longitudinal observational clinical study. Functional testing included randomly Humphrey Matrix perimetry and white-on-white Humphrey visual field perimetry. Ibopamine test was performed in all forty patients. The cut-off of $3 \mathrm{mmHg}$ was considered positive for this provocative test.

Results: Out of 40 patients, we included 21 in ibopamine positive group and 19 in ibopamine negative group. These two groups are sex- and age-matched. In ibopamine positive group the mean increase in IOP is $4.6 \mathrm{mmHg}$ (ranging from 3 to $10 \mathrm{mmHg}$ ). Statistics showed that correlation between FDT and SAP was statistically significant in ibopamine negative group and not statistically significant in ibopamine positive group. Only one patient, coming from IBO + group, converted from ocular hypertension to glaucoma. All the other subjects remained stable in both groups without any therapy and visual field abnormalities.

Conclusions: FDT showed to be more sensitive and specific than SAP mostly in detection of early visual field impairment in ocular hypertensive patients.
\end{abstract}

Keywords: Early glaucoma, FDT, ibopamine, ocular hypertension, SAP.

\section{INTRODUCTION}

Frequency doubling technology (FDT) perimetry measures contrast sensitivity. This test is based on an illusion occurring when a sinusoidal grating of low spatial frequency undergoes counterphase flickering at a high temporal frequency [1-3]. Recent evidences suggest that the magnocellular (MGC) pathway in human retina is isolated as a whole by the FDT stimulus. The variability of FDT is independent of visual field loss $[2,3]$. FDT seems to be a useful clinical tool to detect mostly early manifest glaucoma. The Humphrey Matrix was commercially introduced in 2003 with the following tests: macula 10-2, N-30-F, 24-2 and 30-2 (Fig. 1). The Glaucoma Hemifield Test (GHT) is available for the FDT 24-2 and 30-2 tests. Recent papers studied the learning effect of Matrix FDT and the Authors stressed that it may affect only the first test [4] rather than standard automated perimetry (SAP). Some years ago, the Ocular Hypertension Treatment Study (OHTS) started in the U.S.A. to evaluate the safety and efficacy of topical ocular hypotensive medication in preventing or delaying the onset of visual field loss and/or optic nerve damage in subjects affected by ocular hypertension at moderate risk for developing open-angle glaucoma (OAG) [5]. In U.S.A. it is estimated that 3 to 6 million people, including $4 \%$ to $7 \%$ of the population older than age 40 years, have elevated intraocular pressure (IOP) without detectable glaucomatous damage using current clinical tests

*Address correspondence to this author at the Medical School, University of Roma "Tor Vergata", Via Seneca, 34, 00136 Roma, Italy;

Tel/Fax: ++390635341166; E-mail: italogiuffre@libero.it
[6-13]. Also the pattern electroretinogram was evaluated in glaucoma and ocular hypertensive patients [14]. The aim of this study is to investigate the role of Humphrey Matrix threshold testing in the detection of early functional retinal impairment in ocular hypertensive patients compared to standard automated perimetry.

\section{MATERIALS AND METHODS}

Forty hypertensive subjects (19 male and 21 female), mean age 62.92 (SD 12.23) years were enrolled in this longitudinal observational clinical study. All the study participants gave their informed consent. Inclusion criteria were: age $>18$ years, clear lens and ocular hypertension $(\mathrm{OH}) . \mathrm{OH}$ was defined as: central corneal thickness-adjusted intraocular pressure $(\mathrm{IOP})>21 \mathrm{mmHg}$ [15], under diurnal tonometric curve, open angle gonioscopy, no visual field damage and no systemic and/or topical hypotensive therapy. Exclusion criteria were: spherical refractive error $> \pm 6$ diopters; astigmatism $> \pm 3$ diopters; active or previous retinal pathologies; diagnosis of glaucoma; opacities of dioptric media that could bias functional and structural retinal testing; history of ocular surgery; any fluorangiographic sign of retinal vasculopathy due to diabetes; or other local or systemic disease. All subjects underwent a complete ophthalmological examination including: best-corrected visual acuity (BCVA), Goldmann applanation tonometry, ibopamine test according to Virno et al. [16], slit-lamp examination and indirect ophthalmoscopy. Functional testing included Humphrey Matrix perimetry and white-on-white 30-2 SITA standard Humphrey visual field perimetry (HFA; Carl Zeiss Meditec, Dublin, 


\begin{tabular}{|l|c|c|c|c|c|c|}
\hline \multicolumn{1}{|c|}{ FDT Test } & $\begin{array}{c}\text { Visual } \\
\text { Field } \\
\text { Locations }\end{array}$ & $\begin{array}{c}\text { Probability } \\
\text { Level } \\
\text { Classifications }\end{array}$ & $\begin{array}{c}\text { Fixation } \\
\text { Catch } \\
\text { Trials }\end{array}$ & $\begin{array}{c}\text { False } \\
\text { Positive } \\
\text { Trials }\end{array}$ & $\begin{array}{c}\text { False } \\
\text { Negative } \\
\text { Trials }\end{array}$ & $\begin{array}{c}\text { Test } \\
\text { Strategy }\end{array}$ \\
\hline $\begin{array}{l}\text { N-30-5, } \\
\text { N-30-1 } \\
\text { Screening }\end{array}$ & 19 & 4 & 3 & 3 & 0 & $\begin{array}{c}\text { Supra- } \\
\text { Threshold }\end{array}$ \\
\hline $\begin{array}{l}24-2-5, \\
24-2-1\end{array}$ & 55 & 2 & 10 & 10 & 0 & $\begin{array}{c}\text { Supra- } \\
\text { Screening }\end{array}$ \\
\hline $\begin{array}{l}\text { N-30-F } \\
\text { Threshold }\end{array}$ & 19 & 4 & 6 & 6 & 3 & MOBS \\
\hline $\begin{array}{l}24-2 \\
\text { Threshold }\end{array}$ & 55 & 4 & 10 & 10 & 6 & ZEST \\
\hline $\begin{array}{l}30-2 \\
\text { Threshold }\end{array}$ & 69 & 4 & 10 & 10 & 6 & ZEST \\
\hline $\begin{array}{l}10-2 \\
\text { Threshold }\end{array}$ & 44 & 4 & 10 & 10 & 6 & ZEST \\
\hline $\begin{array}{l}\text { Macula } \\
\text { Threshold }\end{array}$ & 16 & 4 & 6 & 3 & 0 & ZEST \\
\hline
\end{tabular}

Fig. (1). FDT technical features.

Ca., U.S.A.). All enrolled subjects performed at least two Humphrey visual field perimetry and Matrix visual field tests within two weeks using the 30-2 threshold program in order to assess the test-retest variability and to rule out a relevant learning curve. In all cases the first test was not considered [4]. Reliability criteria were defined as less than 33\% fixation errors, false-positives and false-negatives. Pattern standard deviation (PSD) values were considered for the analysis. Corneal pachymetry from limbus to limbus was performed by the high resolution (HR) Oculus Pentacam. It is a rotating Scheimpflug camera which generates images from the anterior surface of the cornea to the posterior surface of lens. It acquires 50 Scheimpflug images in two seconds. The software generates a three-dimensional model of each surface as a basis for corneal topographic and chamber analysis. The rotating camera offers anterior segment images in three dimensions, creating a movable three-dimensional presentation of the anterior chamber. The centre of the cornea is measured very precisely because of this rotating imaging process.

The $2 \%$ ibopamine test was performed according to Virno et al. [16-18]. 2\% ibopamine (Trazyl®, Angelini Acraf, Pomezia, Rome, Italy) stimulates $\alpha$-adrenergic receptors and D1-dopaminergic receptors in the eye. This pharmacological and provocative test is positive if, after 45 minutes after the instillation of ibopamine eye drops, IOP increases by at least $3 \mathrm{mmHg}$. All the ibopamine tests were performed at the same time, even if the increase of the IOP is absolutely independent of the time of day and of the baseline IOP (IOP measured before the instillation of ibopamine eye drops). This provocative test is widely used in Italy and sometimes may be more useful than others such as the water-drinking test [19]. All hypertensive patients were divided in two groups: ibopamine positive (IBO+) and ibopamine negative (IBO-). All patients were classified by Scoring Tool for Assessing Risk (S.T.A.R. I and II version) [20]. According to the Ocular Hypertension Treatment Study and the European Glaucoma Prevention Study (E.G.P.S.) these predictive parameters were identified as: age, IOP, central corneal thickness (CCT), vertical cup-to-disc ratio, and Humphrey visual field pattern standard deviation. This method, in both versions I and II, gives a percentage of probability of conversion from $\mathrm{OH}$ to glaucoma. In this way, it gives some information that the clinician may use to make a decision about diagnosis and mostly about therapy and follow-up. Statistical analysis was performed by descriptive statistics, analysis of variance (ANOVA), Bland-Altman method and Spearman analysis.

\section{RESULTS}

Out of 40 patients, according to the ibopamine test we included 13 males and 8 females in IBO + group. In this group both eyes were positive to this test. The mean age of this group is 60.38 (SD 12.71) years. The remaining 19 subjects (6 males and 13 females) were included in the IBO group. The mean age of the second group is 64.53 (SD 11.27) years. By chance it happened that the two groups are sex- and age-matched $(\mathrm{p}=0.284)$. Pachymetrical data are in Fig. (2). The mean follow-up in IBO + group is 17.48 months, in IBO - group is 17.5 months. The follow-up of both groups is homogeneous $(\mathrm{p}=0.997)$. In ibopamine positive group the mean IOP increase is $4.6 \mathrm{mmHg}$ (ranging from 3 to $10 \mathrm{mmHg}$ ). S.T.A.R. I vs S.T.A.R. II measurements in both IBO + and IBO - groups are in Figs. (3-5), according to Bland-Altman method. Spearman correlation ranking between FDT and SAP visual field tests was statisti- 
cally significant in IBO - group $(\mathrm{p}<0.02$, Fig. 6) but not statistically significant in IBO + group $(p>0.05$, Fig. 7). In the whole population studied, only one patient (I.C., male, 45 years old), belonging to the IBO + group, had a conversion from ocular hypertension to open-angle glaucoma during follow-up and started a monotherapy by beta-blocker in both eyes. All the other subjects from both groups (IBO + and IBO -) remained stable during follow-up without any therapy and visual field abnormalities.

\section{PACHYMETRY}
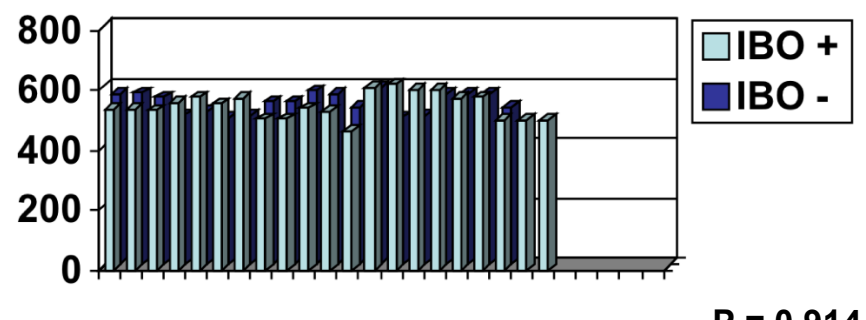

Fig. (2). Pachymetrical data $(\mu)$ on $y$-axis and $n$. of patients on $x$-axis.

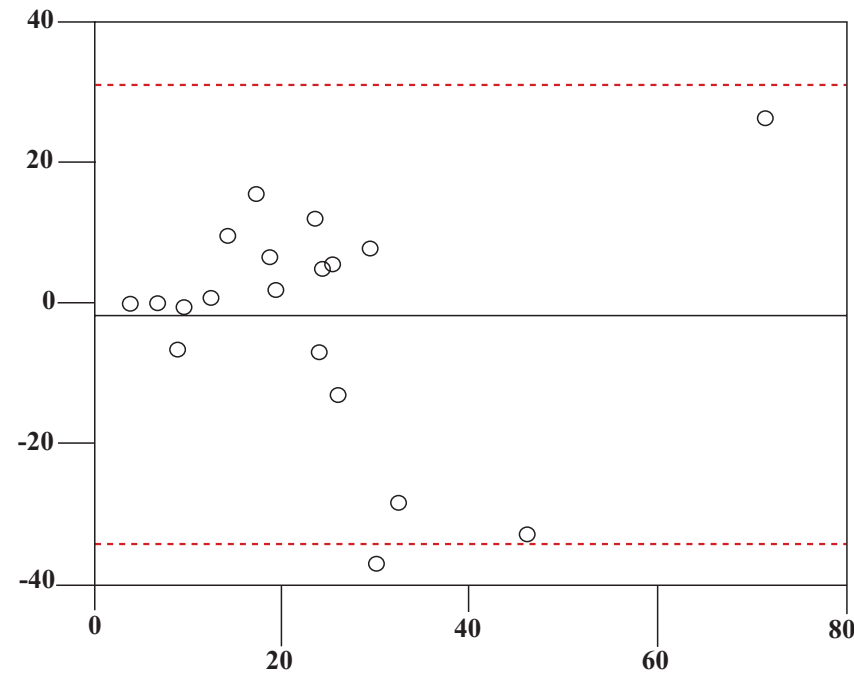

Fig. (3). STAR I (x-axis) vs STAR II (y-axis) in all patients.

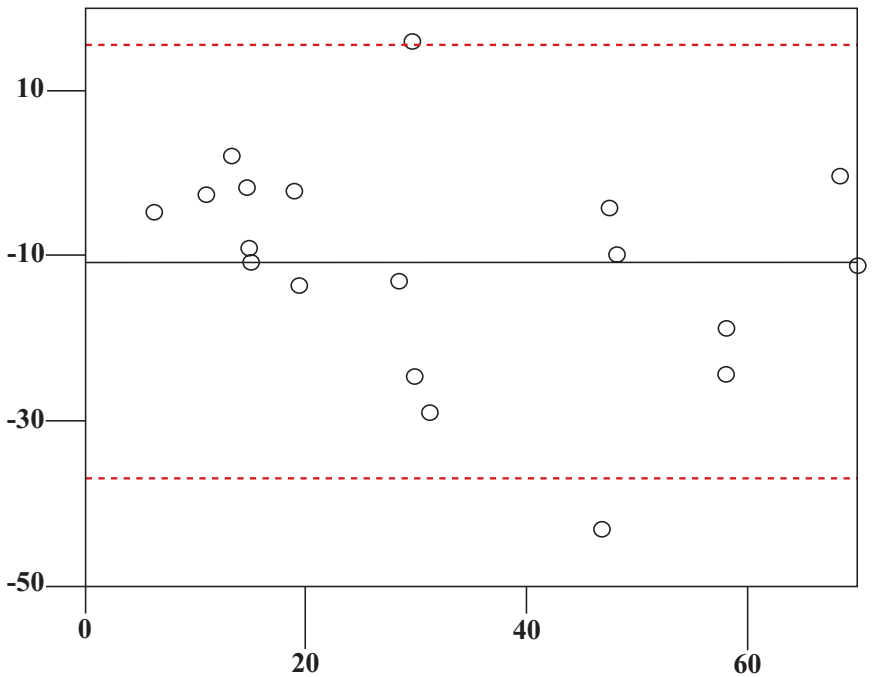

Fig. (4). STAR I (x-axis) vs STAR II (y-axis) in IBO + group.

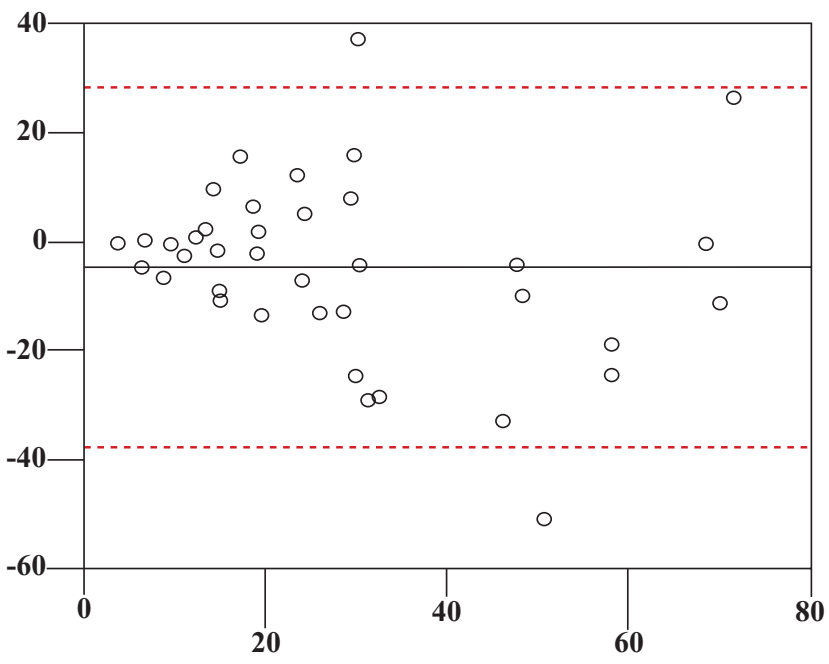

Fig. (5). STAR I (x-axis) vs STAR II (y-axis)in IBO - group.

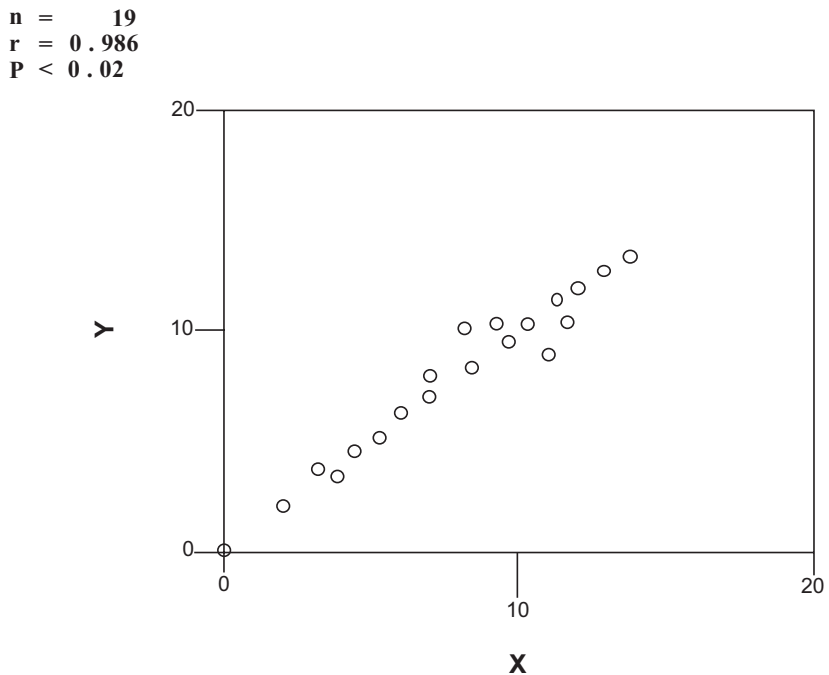

Fig. (6). SAP (x-axis) vs FDT (y-axis) in IBO - group.

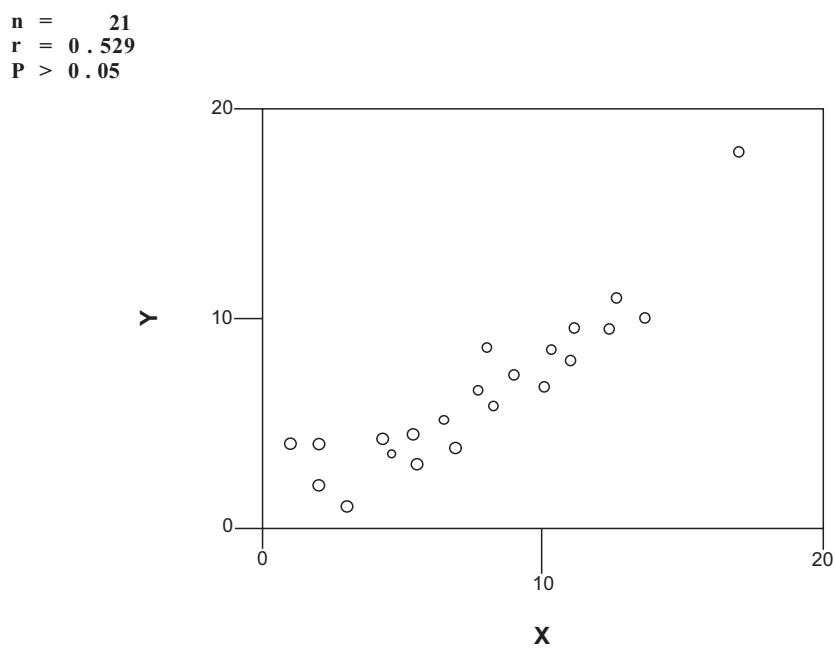

Fig. (7). SAP (x-axis) vs FDT (y-axis) in IBO + group. 


\section{DISCUSSION}

We studied a small but homogeneous cohort of hypertensive patients. This cohort of subjects is sex- and agematched. No statistical difference was evaluated as for pachymetry, S.T.A.R. I and II scores. The HR Pentacam is a very useful tool in evaluating pachymetry very precisely either in normal population, in $\mathrm{OH}$ and glaucoma subjects and in refractive surgery patients. Only in ibopamine negative group we found a statistical significant correlation between FDT and SAP visual field testing. This new pharmacological and provocative test (ibopamine test) is very interesting and useful in evaluating the possibility to convert from $\mathrm{OH}$ to glaucoma, also in relatives of glaucoma patients [21]. It is very easy to use and allows a very important non-cycloplegic mydriasis, useful also in diagnostic testing of outflow impairment. It is safe. In Literature there are no significant side-effects described. In $\mathrm{OH}$ subjects, such as in normal tension glaucoma, its positivity is about $52 \%$. We can speculate that, as in Weinreb's glaucoma continuum [22] and from genetical point of view, $\mathrm{OH}$ is just a step towards open-angle glaucoma and like a "relative" of normal tension glaucoma. As we know that Humphrey Matrix threshold testing selectively stimulates the magno-cellular component of ganglion cells (3), we underline that this diagnostic tool, associated with ibopamine test, can be useful for the identification of early visual field impairment in ocular hypertensive subjects, suggesting a possible conversion from $\mathrm{OH}$ to open-angle glaucoma [23]. It may be also useful in the follow-up of glaucoma patients even if SAP remains the gold standard of our public and private offices.

\section{REFERENCES}

[1] Racette L, Medeiros FA, Zangwill LM, et al. Diagnostic accuracy of the Matrix 24-2 and original N-30 frequency-doubling technology tests compared with standard automated perimetry. Invest Opthalmol Vis Sci 2008; 49 (3): 954-60.

[2] Parravano M, Oddone F, Mineo D, et al. The role of humphrey matrix testing in the early diagnosis of retinopathy in type 1 diabetes. Br J Ophthalmol 2008; 92: 1656-60.

[3] White AJR, Sun H, Swanson WH, Lee BB. An examination of physiological mechanisms underlying the frequency-doubling illusion. Invest Opthalmol Vis Sci 2002; 43: 3590-9.

[4] Centofanti M, Fogagnolo P, Oddone F, et al. Learning effect of Humphrey matrix frequency doubling technology perimetry in patients with ocular hypertension. J Glaucoma 2008; 17 (6): 436-41.

[5] Gordon MO, Kass MA. The ocular hypertension treatment study: design and baseline description of the participants. Arch Ophthalmol 1999; 117 (5): 573-83.

[6] Johnson CA, Keltner JL, Cello KE, et al. Baseline visual field characteristics in the ocular hypertension treatment study. Ophthalmology 2002; 109 (3): 432-7. treatment study: baseline factors that predict the onset of primary open-angle glaucoma. Arch Ophthalmol 2002; 120 (6): 714-20.

8] Brandt JD, Beiser JA, Gordon MO, et al. Central corneal thickness and measured IOP response to topical ocular hypotensive medication in the ocular hypertension treatment study. Am J Ophthalmol 2004; 138 (5): 717-32.

[9] Medeiros FA, Weinreb RN, Sample PA, et al. Validation of a predictive model to estimate the risk of conversion from ocular hypertension to glaucoma. Arch Ophthalmol 2005; 123 (10): 1351-60.

[10] Levine RA, Demirel S, Fan J, et al. Asymmetries and visual field summaries as predictors of glaucoma in the ocular hypertension treatment study. Invest Opthalmol Vis Sci 2006; 47 (9): 3896-903.

[11] Budenz DL, Anderson DR, Feuer WJ, et al. Detection and prognostic significance of optic disc hemorrhages during the Ocular Hypertension Treatment Study. Ophthalmology 2006; 113 (12): 2137-43.

[12] Herman DC, Gordon MO, Beiser JA, et al. Topical ocular hypotensive medication and lens opacification: evidence from the ocular hypertension treatment study. Am J Ophthalmol 2006; 142 (5): 800-10.

[13] Bozkurt B, Yilmaz PT, Irkec M. Relationship between humphrey 30-2 SITA standard test, matrix 30-2 threshold test, and Heidelberg retina tomography in ocular hypertensive and glaucoma patients. J Glaucoma 2008; 17 (3): 203-10.

[14] O'Donaghue E, Arden GB, O'Sullivan F, et al. The pattern electroretinogram in glaucoma and ocular hypertension. Br J Ophthalmol 1992, 76, 387-94.

[15] Doughty MJ, Zaman ML. Human corneal thickness and its impact on intraocular pressure measures: a review and meta-analysis approach. Surv Ophthalmol 2000; 44: 367-408.

[16] Virno M, Pecori-Giraldi J, Taverniti 1, et al. Intraocular hypertensive effects of topically administered ibopamine in eyes with hydrodynamic disorders: provocative test for glaucoma. Glaucoma 1990; 12: 88-92.

[17] Giuffre' I. Ibopamine stimulates $\alpha$-adrenergic receptors and D1 dopaminergic receptors in the eye. Curr Drug Ther 2007; 2(2): 12732 .

[18] Giuffre' I, Taverniti L, Di Staso S. The effects of 2\% ibopamine eye drops on the intraocular pressure and pupil motility of patients with open-angle glaucoma. Eur J Ophthalmol 2004; 14, 6:508-13.

[19] Vetrugno M, Sisto D, Trabucco T, et al. Water-drinking test in patients with primary open-angle glaucoma while treated with different topical medications. J Ocul Pharmacol Ther 2005; 21 (3): 2507.

[20] Gordon MO, Torri V, Miglior S, et al. Ocular hypertension treatment study group, European glaucoma prevention study group, validated prediction model for the development of primary openangle glaucoma in individuals with ocular hypertension. Ophthalmology 2007; 114(1): 10-9.

[21] Pecori-Giraldi J, Damiano A, Gabrielli A, et al. Ocular hypertension induced by ibopamine early discloses glaucoma suspects among relatives of glaucomatous patients. Boll Ocul 2002; 81:91.

[22] Weinreb RN, Friedman DS, Fechtner RD, et al. Perspective. Risk assessment in the management of patients with ocular hypertension. Am J Ophthalmol 2004; 138: 458-67.

[23] De Gregorio F, Pecori-Giraldi J, De Stefano C, Virno M. Correlation between ocular hypertension induced by ibopamine and perimetric defect in primary open-angle glaucoma. Eur J Ophthalmol 1997; $7:$ 152-5.

This is an open access article licensed under the terms of the Creative Commons Attribution Non-Commercial License (http: //creativecommons.org/licenses/by$\mathrm{nc} / 3.0 /$ ) which permits unrestricted, non-commercial use, distribution and reproduction in any medium, provided the work is properly cited. 